\title{
CLINICAL-RADIOLOGICAL ASPECTS OF PRIMARY EXTRACRANIAL MENINGIOMA OF THE ETHMOID SINUS IN A CHILD
}

\author{
José Roberto Lopes Ferraz-Filho', Valdeci Hélio Floriano², \\ Leonardo Franco Felipe ${ }^{2}$, José Alves Rocha-Filho ${ }^{3}$
}

Meningiomas are tumors of benign histological nature which represent 13 to $26 \%$ of all primary intracranial neoplasia'. Approximately $20 \%$ of intracranial meningiomas present extracranial dissemination at sites such as the orbit, middle ear, nasal cavity, nasopharynx and paranasal sinuses ${ }^{2}$. Primary extracranial meningiomas are histologically identical to intracranial meningiomas. They usually occur in 40 to 60 -year-old patients and are rare in the pediatric age group. Primary extracranial meningiomas represent 1 to $2 \%$ of all meningiomas ${ }^{1-5}$.

We to report the case of a 13-year-old girl with a primary extracranial meningioma of the ethmoid sinus, including the main findings of the imaging examination and a brief review of the literature.

\section{CASE}

A 13-year-old girl was referred to our service with a 30-day history of constant and strong frontal headache, nasal obstruction, and progressive proptosis of the left eye without signs of phlogiston or alterations in visual acuity.

At rhinoscopy, a lesion of the soft tissues was observed occupying the left superior meatus of the nasal cavity with a smooth pink surface.

In light of these findings, a CT of the skull and face sinuses was performed showing an extensive hypodense non-calcified lesion measuring $2.0 \times 2.0 \mathrm{~cm}$ located in the left ethmoid sinus. The lesion presented heterogeneous iodinated contrast enhancement and demonstrated remodeling of the adjacent bone structures (Fig 1).

MRI of the facial sinuses was requested to evaluate the involvement of the soft structures as well as the invasion of the adjacent structures and resection planes. The lesion in the left ethmoid sinus was hypointense in $\mathrm{T} 1$ and $\mathrm{T} 2$-weighted sequences, with heterogeneous paramagnetic contrast enhancement, determining a mass effect on the adjacent structures, lateral divergence of the medial rectus muscle of the left orbit, but with-

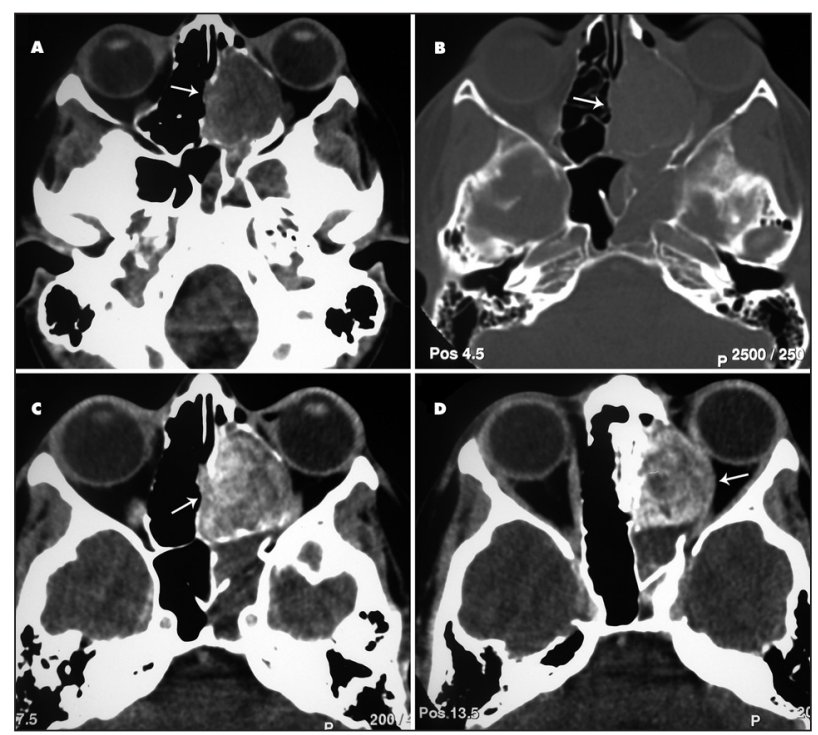

Fig 1. CT: $(A, B)$ axial image showing lesion in the left ethmoid sinus with $C T$ hypodense aspect, without calcification and with remodeling of the adjacent bone structures. (C,D) axial image showing iodinated contrast heterogeneous enhancement of the lesion.

out invasion (Fig 2). Additionally, maxillary and sphenoidal sinus disease was observed.

The patient was submitted to excision of the lesion by external and endoscopic ethmoidectomy with a complete cure of the exophthalmus in the postoperative period. Diagnosis of atypical meningioma was attained by histopathological examination.

\section{DISCUSSION}

The present study shows the clinical and imaging aspects of primary extracranial meningioma of the ethmoid sinuses in a child. Primary extracranial meningioma of the nasal cavity or paranasal sinuses is rare, especially in children. The paranasal sinuses most commonly affected are the frontal, maxillary, ethmoid and sphenoid sinuses ${ }^{2,3,5}$.

\section{ASPECTOS CLÍNICO-RADIOLÓGICOS DE MENINGIOMA PRIMÁRIO DO SEIO ETMOIDAL EM CRIANÇA}

Image Department, Medical School, São José do Rio Preto SP, Brazil (FAMERP): 'MD, Image Department, FAMERP; ${ }^{2}$ MD, Fellow at the Image Department, FAMERP; ${ }^{3}$ MD, Fellow at the Cardiac Image, INCOR, Hospital das Clínicas, Faculdade de Medicina da Universidade de São Paulo, Brazil (HCFMUSP).

Received 18 September 2007, received in final form 7 December 2007. Accepted 8 February 2008.

Dr. José Roberto Lopes Ferraz-Filho - Avenida Brigadeiro Faria Lima 5544 - 15090-000 São José do Rio Preto SP - Brasil. E-mail: jrl.ferraz@terra.com.br 


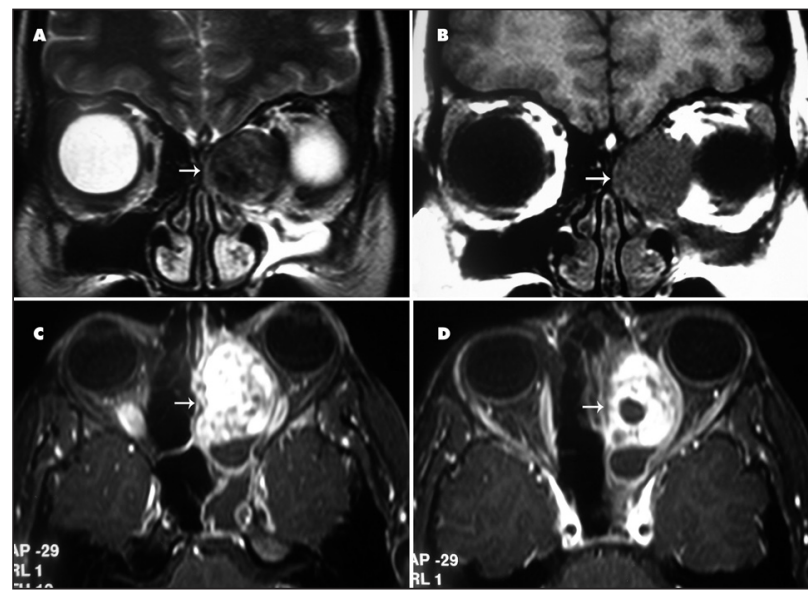

Fig 2. MRI: $(A, B)$ axial image showing lesions hypointense in $T 2$ and T1-weighted sequences in the left ethmoid sinus. $(C, D)$ T1-weighted axial image showing paramagnetic contrast heterogeneous enhancement of the lesion.

According to published data, the first description of primary extracranial meningioma of the paranasal sinuses was in 1931, after which 40 cases have been described. And only three cases involved the ethmoid sinuses with only one case in the pediatric population ${ }^{1,3,4-7}$.

The symptoms are specific for paranasal sinuses or related to the involvement of adjacent structures. The most common complaints are sinusitis, nasal mass and epistaxis ${ }^{2}$. Nasal obstruction, headaches and proptosis are also frequent complaints as were observed in the current case.

Although meningioma is a tumor generally found at an intracranial location derived from meningocytes found in the meninges, in approximately $20 \%$ of cases it presents an extracranial extension due to continuity ${ }^{2,3}$. The nasal cavity, as well as the paranasal sinuses, does not have this type of tissue, hence the rarity of the involvement of these regions. Some theories have been proposed to explain the primary origin of meningiomas at these locations. The main ones are related to: a) the presence of arachnoid cells in nerve sheaths or in vessels where they emerge from the central nervous system, b) the migration of tissue from the meninges to extracranial regions during embryogenesis, c) traumatic events or intracranial hypertension that displaces arachnoid cells and finally, d) undifferentiated mesenchymal cells ${ }^{1-3}$.

Meningiomas in children tend to present atypical characteristics in imaging examination, including cysts, hemorrhage, aggressiveness and uncommon locations ${ }^{4}$.

Computed tomography better demonstrates the presence of intratumoral calcification, the hyperdense aspect of the lesion and homogeneous iodinated contrast enhancement. The MRI supplies more precise information related to the extension and tumoral invasion of adjacent structures, characterized by a increased $\mathrm{T} 1$ and $\mathrm{T} 2$ weighted signal intensity and with the same pattern of the contrast enhancement of $\mathrm{CT}^{8,9}$. However, in the case described herein, the lesion presented a heterogeneous contrast enhancement, hypodense aspect at CT and without intratumoral calcification, which may be related to the atypical aspects of meningiomas in children.

The differential diagnosis of extracranial meningiomas located in the nasal sinus region, should include mucocele, olfactory neuroblastoma, carcinoma, hemangioma, sarcoma and angiofibroma $a^{2,3}$.

Treatment of primary extracranial meningioma of paranasal sinuses is based on total surgical resection of the lesion through endoscopy or open surgery. When it is not possible to perform total surgical resection of the lesion as a result of the complex anatomy of both nasal cavity and paranasal sinuses, adjuvant therapeutic options is restrict to radiation therapy and chemotherapy ${ }^{1-3,10,11}$.

In general, the prognosis is good. In cases of tumor recurrence, the tumor usually arise in the same anatomic site as the primary tumor and probably represent the residual disease rather than recurrent tumor ${ }^{2}$.

In the present case, the patient was submitted to a total surgical exeresis of the lesion through an external ethmoidectomy and endonasal combined approach. There was no evidence of tumor recurrence during the two years of post-surgical follow-up.

\section{REFERENCES}

1. Kainuma K, Takumi Y, Uehara T, Usami S. Meningioma of the paranasal sinus: a case report. Auris Nasus Larynx 2007;34:397-400.

2. Thompson LDR, Gyure KA. Extracranial sinonasal tract meningiomas. Am J Surg Pathol 2000;24:640-650.

3. Gökduman CA, Iplikcioglu AC, Kuzdere M, Bek S, Cosar M. Primary meningioma of the paranasal sinus. J Clin Neurosc 2005;12:832-834.

4. Rondinelli PIP, Viana CR, Osório CAM, Sredni ST. Extenso meningioma atípico na infância. Arq Neuropsiquiatr 2003;61:695-698.

5. García-Purriños FJ, Cervilla AR, Lemberg P, Moya JC. Meningioma maligno nasal. Acta Otorrinolaringol Esp 2005;56:373-375.

6. Petrulionis M, Valeviciene N, Paulauskiene I, Bruzaite J. Primary extracranial meningioma of the sinonasal tract. Acta Radiol 2005;46:415-418.

7. Zhou X, Li J, Peng T. Report of 4 cases ectopic meningioma of maxillary sinus in children and the review of relative literatures. Lin Chuang Er Bi Yan Hou Ke Za Zhi 2005;19:490-491.

8. Hanada M, Kitajima K. Primary ectopic meningioma in the right ethmoid sinus: a case report. Auris Nasus Larynx 1997;24:321-324.

9. Whittle IR, Smith C, Navoo P, Collie D. Meningiomas. Lancet 2004;363: 1535-1543.

10. Swain RE, Kingdom TT, Delgaudio JM, Muller S, Grist W J. Meningiomas of the paranasal sinuses. Am J Rhinology 2001;15:27-30.

11. Goyal LK, Suh JH, Mohan DS, Prayson RA, Lee J, Barnett GH. Local control and overall survival in atypical meningioma: a retrospective study. Internat J Radiation Oncol Biol Physics 2000;46:57-61. 